\title{
Relation between Human Chorionic Gonadotropin and Thyroid Hormones in Preeclampsia
}

\author{
María I. Camejo ${ }^{*}$, Ysabel C. Casart ${ }^{2 * \#}$ \\ ${ }^{1}$ Departamento de Biología de Organismos, Universidad Simón Bolívar, Baruta, Venezuela \\ ${ }^{2}$ Escuela de Nutrición y Dietética, Facultad de Medicina, Universidad Central de Venezuela, Caracas, Venezuela \\ Email: " casarty@hotmail.com
}

Received 5 August 2014; revised 30 September 2014; accepted 2 November 2014

Copyright (C) 2014 by authors and OALib.

This work is licensed under the Creative Commons Attribution International License (CC BY). http://creativecommons.org/licenses/by/4.0/

(c) (i) Open Access

\section{Abstract}

Aim: Alterations in thyroid function with a simultaneous increase of hCG in some pregnancy diseases have been reported. However, the relationship between thyroid hormones and hCG during preeclampsia is not yet evaluated. In this study we determined serum levels of hCG, TSH, free T3 (fT3) and free T4 (fT4) in normal pregnant woman and in patients with preeclampsia and evaluated the correlation between these hormones. Methods: Blood samples were taken from 20 healthy pregnant women as control and from 20 patients with severe preeclampsia. Total hCG was measured by enzyme immunoassays. Serum concentrations of TSH, fT3 and fT4 were determined by chemiluminiescence method. Result: The average values of hCG were higher in the group with preeclampsia, but no statistically significant differences in relation to control group were observed. Likewise, no differences in serum concentrations of TSH, fT3 and fT4 between the control group and the group with preeclampsia were observed. Additionally, no correlation was observed between TSH, T3 and T4 with hCG. Conclusion: No correlation was observed between hCG and thyroid hormones. The different forms of hCG present in normal pregnancy and during preeclampsia could have different ways of stimulating the TSH receptor, which may be reflected in thyroid function.

\section{Keywords}

Human Chorionic Gonadotropin, TSH, T4, T3, Thyroid, Preeclampsia, Pregnancy

Subject Areas: Clinical Trials, Women's Health

\footnotetext{
*The authors contributed equally to this work.

${ }^{\#}$ Corresponding author.
} 


\section{Introduction}

Pregnancy is associated with substantial but reversible changes in thyroid function [1] [2]. The physiological changes in the thyroid gland during pregnancy are well understood, but only a few reports provide information about thyroid function in complicated pregnancies [1]. Although pregnancy is usually associated with very mild hyperthyroxinemia, women with hypothyroidism increase the risk for obstetrical complications as gestational hypertension or preeclampsia [3]. Several investigations [4]-[7] reported that preeclamptic women had significantly increased seric concentrations of thyrotropin (TSH) and decreased concentrations in free triiodothyronine (fT3) and free thyroxine (fT4), in relation to normotense pregnant women, in the third trimester. However, fT3, fT4 and TSH remained within the reference range.

There are controversies about the mechanism and clinical significance of low concentration of thyroid hormones in preeclampsia. Research groups [4] [8] reported that compared to the controls, the preeclamptic patients had low fT4 and fT3 concentrations and observed that preeclamptic patients with low fT4/fT3 had significantly higher plasma urate and albumin concentrations. Therefore, the authors suggest that the thyroid hormones concentrations may reflect the severity of preeclampsia. Additionally, it has been proposed that alteration in thyroid functions during preeclampsia might result from the dysfunction in the hypothalamic-pituitary-thyroid axis, secondary to the disease itself [9]. However, other authors found no alteration in thyroid function during preeclampsia [10]. Moreover, recent reports show that both hypothyroidism and hyperthyroidism are associated with preeclampsia [11]-[13].

On the other hand, several studies have reported an association between unexplained elevation in maternal serum human chorionic gonadotropin (hCG), and preeclampsia [14]-[20]. Additionally, an increase in thyroid function has been reported in patients with trophoblastic tumor, either hydatidiform mole or choriocarcinoma [21]-[23] or in hyperemesis gravidarium [24], with a simultaneous increase of hCG. However, the relationship between thyroid hormones and hCG during preeclampsia has not yet been evaluated.

The aim of this study was to determine serum levels of hCG, TSH, free T3 (fT3) and freeT4 (fT4) in normal pregnant woman and in patients with preeclampsia and the possible correlation between these hormones.

\section{Methods}

This investigation was a case-control study; subjects were selected randomly from a population of patients admitted at the Concepcion Palacios Maternity Hospital (Caracas, Venezuela) with a diagnosis of preeclampsia. The control group was recruited from normotensive pregnant women attending prenatal clinic. The study was approved by the institutional Review Board of the Concepcion Palacios Maternity Hospital and its Bioethics Committee, and all women signed informed consent. Preeclamptic patients were identified after detection of proteinuria ( $\geq 500 \mathrm{mg} /$ day), blood pressure $\geq 140 / 90 \mathrm{mmHg}$, or a rise of $30 \mathrm{mmHg}$ in systolic pressure or of 15 mmHg in diastolic pressure (in at least two consecutive 6 hours apart measurements while at bed rest) and edema. Pregnant women control-group had no history of hypertension and no evidence of hypertension or proteinuria during current pregnancy. There was not statistical difference in maternal age between the groups. All the subjects were in the third trimester of pregnancy, and presented similar median gestational age. All patients who had a history of any thyroid disorders, renal disease, or chronic hypertension; or those who were on medications (such as diuretics, corticosteroids or antihypertensive, which could alter thyroid function test) were excluded. Blood samples were obtained at time of diagnosis of preeclampsia, or during check-up of normotensive women. Serum was separated and stored at $-20^{\circ} \mathrm{C}$ to be evaluated later. Total hCG (nicked + non nicked + free) immunoreactivity was measure by enzyme immunoassays kit (Chiron Diagnostic, Emeryville, CA, USA), with a sensitivity of $2.0 \mathrm{mUI} / \mathrm{mL}$ and with a variation coefficient between-assays of $3.8 \%$. The thyroid hormones were measured by chemiluminescence method. Thyrotropin (TSH) and concentrations expressed in mUI/mL and free T4, free T3 in ng/dl.

Statistical analysis was performed by Student $t$ test, and Pearson correlation test, using the software Statistica. Results were expressed as mean \pm SEM and $p$ values $\leq 0.05$ were accepted as statistical significant.

\section{Results}

Clinical and demographic data are given in Table 1. There were no significant differences in maternal age, gestational age and parity at the sampling time, between preeclamptic and normotensive group. Table 2 lists the average concentration of hCG, TSH, fT3 and fT4 in the normotensive and in the preeclamptic group. The hCG 
Table 1. Women clinical characteristics.

\begin{tabular}{lcc}
\hline & $\begin{array}{c}\text { Normotensive group } \\
(\mathrm{n}=20)\end{array}$ & $\begin{array}{c}\text { Preeclamptic group } \\
(\mathrm{n}=20)\end{array}$ \\
\hline Maternal age (year) & $25.30 \pm 1.31$ & $28.83 \pm 1.18$ \\
Week of Gestation ${ }^{*}$ & $35.3 \pm 1.48$ & $33.13 \pm 0.98$ \\
Parity & & $\mathrm{ns}$ \\
$\quad$ Nuliparous & 16 & 18 \\
$\quad$ Multiparous & 4 & $\mathrm{~ns}$ \\
\hline
\end{tabular}

*At sampling time. The values represent the mean \pm SEM. ns = not statistically significant.

Table 2. Serum concentration of hCG, TSH, frees T3 and free T4 in normotensive and preeclamptic women.

\begin{tabular}{ccccc}
\hline Group & hCG $(\mathrm{IU} / \mathrm{ml})$ & $\mathrm{TSH}(\mu \mathrm{UI} / \mathrm{mL})$ & free T3 $(\mathrm{pg} / \mathrm{dl})$ & free T4 (ng/dl) \\
\hline $\begin{array}{c}\text { Normotensive } \\
(\mathrm{n}=20)\end{array}$ & $21445 \pm 3422$ & $2.5 \pm 1.2$ & $3.35 \pm 0.65$ & $1.0 \pm 0.2$ \\
$\begin{array}{c}\text { Preeclamptic } \\
(\mathrm{n}=20)\end{array}$ & $28624 \pm 4816$ & $2.6 \pm 1.6$ & $2.99 \pm 0.88$ & $1.0 \pm 0.4$ \\
\hline
\end{tabular}

The values represent the mean \pm SEM. $\mathrm{p}>0.05$. No statistically significant difference was observed between groups.

concentration was higher in the preeclamptic (28624 $44816 \mathrm{UI} / \mathrm{ml}$, minimum 6778 and maximum $99512 \mathrm{UI} / \mathrm{ml})$ than in the normotensive group (21445 $\pm 3422 \mathrm{UI} / \mathrm{ml}$, range 33662 - $52392 \mathrm{UI} / \mathrm{ml}$ ) but the observed difference was not statistically significant. Serum concentration of TSH was similar in the preeclamptic $(2.6 \pm 1.6 \mathrm{mUI} / \mathrm{ml}$ range $0.3-6.5 \mathrm{mUI} / \mathrm{ml})$ and in the normotensive group $(2.5 \pm 1.2 \mathrm{mUI} / \mathrm{ml}$, minimum 1.0 and maximum 5.3 $\mathrm{mUI} / \mathrm{ml})$. There was not difference in fT3 serum levels between the preeclamptic (2.99 $\pm 0.88 \mathrm{ng} / \mathrm{dl}$, range 2.05 $3.98 \mathrm{ng} / \mathrm{dl}$ ) and the normotensive group (3.35 $\pm 0.65 \mathrm{ng} / \mathrm{dl}$ minimum 2.25 maximum $3.97 \mathrm{ng} / \mathrm{dl})$. Serum fT4 was similar in the preeclamptic $(1.0 \pm 0.4 \mathrm{ng} / \mathrm{dl}$, range $0.8-1.5 \mathrm{ng} / \mathrm{dl})$ and normotensive group $(1.0 \pm 0.2 \mathrm{ng} / \mathrm{dl}$, minimum 0.8 and maximum $2.0 \mathrm{ng} / \mathrm{dl})$.

There was no correlation between serum levels of hCG and TSH, hCG and FT3, hCG and fT4, TSH and fT3, TSH and fT4, and fT3 and fT4 (data not shown) neither in the preeclamptic group nor in the normotensive group.

\section{Discussion}

The result of our study showed that thyroid function, based on fT3, fT4 and TSH levels, was not altered in the preeclamptic group compared to the normotensive group. The average values of hCG were higher in the group with preeclampsia, but there was no statistically significant differences in relation to the control group. Additionally, no correlation was observed between TSH, T3 and T4 with hCG.

Thyroid-stimulating activity in serum of normal pregnant women shows a significant correlation with levels of serum hCG levels. It is likely that the thyrotrophic activity of hCG during first trimester peak secretion overrides the normal operation of the hypothalamic-pituitary-thyroid feedback system [25]. An association has been reported in certain pathologies of pregnancy, where there is increase in hCG, as in hyperemesis gravidarium, with an increase in thyroid function [26].

In some cases, the gestational trophoblastic disease is complicated with hyperthyroidism. This is believed to occur because of molecular mimicry between hCG and TSH causing cross-reactivity of the molecule of hCG with the TSH receptor. Treating gestational trophoblastic disease normalizes the hCG levels and hyperthyroidism is resolved [22].

Studies show divergence in relation to the concentration of thyroid hormones and preeclampsia. Several studies [4]-[7] found that preeclamptic women had significantly higher concentrations of TSH and lower fT4 and fT3 compared to normotensive pregnant women in the third trimester. However, Qubland et al. [10] demonstrate that thyroid function was not altered in the preeclamptic group compared to the normotensive. These results agree with those of our study. It has been reported that the technique employed for measuring free hormones concentration could affect concentration value [27]. Similar to Qublan's study [10], we used electrochemioluminicence to measure thyroid hormones, because this method is not influenced by concentrations of albumin in 
serum or blocking antibody [28] [29]. However, the others studies [4]-[7] used radioimmunoassay.

In the present study, hCG concentration was increased in the preeclamptic group compared to the normal pregnancy group, but the difference was not statistically significant. In a previous study from our laboratory, it was shown that hCG concentration was increased in patients with preeclampsia, but the bioactivity of this hormone was decreased [30]. The biologic activity of glycoprotein hormone is influenced by structure and number of oligosaccharide side in $\beta$ subunits. Extensive variations are possible in the branched oligosaccharide structure, contributing to considerable heterogeneity of glycoprotein hormone.

Numerous studies have suggested a link between elevated maternal hCG serum levels and preeclampsia [17]-[20] whereas Huang et al. [31] as well as Wenstrom et al. [32] did not observe significant differences in hCG concentration between preeclamptic and normal pregnancies. Immunodiagnostic kits to determine hCG vary the isoforms detected by the kit (nicked, non nicked, $\beta$-free). Therefore, the results of the different investigations are not always comparable, which could explain the differences in several studies in the relationship between preeclampsia and hCG.

Interestingly, research of hCG molecule has made significant progress in recent years. A review by Cole [33] indicates that there are at least 5 molecules of biologically active hCG: 1 -the hormone produced by the placental syncytiotrophoblast cells, 2-the sulfated hormone produced by the pituitary gonadotrope cells, 3-the hyperglycosylated hCG autocrine made by placental cytotrophoblast cells, 4-the autocrine cancer promoters hyperglycosylated hCG, 5-hCGß and hyperglycosylated hCGß made by all malignancies.

Previous reports showed that variations in hCG glycosylation modified its thyrotropic potency in different cell models in vitro [34]-[37]. Moreover, depending of hCG integrity and glycosilation, different forms of hCG forms molecules could act as an agonist or as an antagonist [38]. HCG hyper-glycosylated forms are dominant in early pregnancy ( 3 - 5 weeks) and choriocarcinome, while it has been described that during preeclampsia a hypo-glycosylated hCG form is present, which makes the invasive process of implantation difficult [39].

\section{Conclusions}

In conclusion, no correlation was observed between hCG and thyroid hormones. The different forms of hCG present in normal pregnancy, preeclampsia and other gestational trophoblastic diseases could have different abilities to stimulate the TSH receptor, which may be reflected in thyroid function. Further studies considering these aspects should be performed.

However, this study has several limitations. The first one is that background information about hCG is from some published reports on preeclampsia measured serum hCG in the second trimester, others in the third trimester serum and still others in placental samples. The same can be for thyroid hormones. Second, we cannot estimate the range of the hCG concentration need that might depress THS levels. Apart from these factors, another reason is that numbers of study subject are too few to determine difference. Therefore, it is necessary for future prospective and large-scale study to clarify the relation between hCG and thyroid hormones in preeclampsia.

\section{Acknowledgements}

The authors wish to thank to Professor Yris Casart for proofreading the manuscript.

\section{Declaration of Interest Statement}

This study was partially supported by $\mathrm{CDCH}$, Universidad Central de Venezuela and Decanato de Investigación y Desarrollo, Universidad Simón Bolívar.

The authors declare no conflicts of interest. Funding came from the universities where they work and it constituted a contribution to the research.

\section{References}

[1] Kumar, A., Ghosh, B.K. and Murthy, N.S. (2005) Maternal Thyroid Hormonal Status in Preeclampsia. Indian Journal of Medical Sciences, 59, 57-63. http://dx.doi.org/10.4103/0019-5359.13904

[2] Kurioka, H., Takahashi, K. and Miyazaki, K. (2005) Maternal Thyroid Function during Pregnancy and Puerperal Period. Endocrine Journal, 52, 587-591. http://dx.doi.org/10.1507/endocrj.52.587 
[3] Wasserstrum, N. and Anania, C.A. (1995) Perinatal Consequences of Maternal Hypothyroidism in Early Pregnancy and Inadequate Replacement. Clinical Endocrinology (Oxford), 42, 353-358.

http://dx.doi.org/10.1111/j.1365-2265.1995.tb02642.x

[4] Lao, T.T., Chin, R.K.H., Swaminathan, R. and Lam, Y.M. (1990) Maternal Thyroid Hormones and Outcome of PreEclamptic Pregnancies. British Journal of Obstetrics \& Gynaecology, 97, 71-74. http://dx.doi.org/10.1111/j.1471-0528.1990.tb01719.x

[5] Vojvodić, L.J., Sulović, V., Pervulov, M., Milacić, D. and Terzić, M. (1993) The Effect of Pre-Eclampsia on Thyroid Gland Function. Srpski Arhiv za Celokupno Lekarstvo, 121, 4-7.

[6] Khaliq, F., Singhal, U., Arshad, Z. and Hossain, M.M. (1999) Thyroid Functions in Pre-Eclampsia and Its Correlation with Maternal Age, Parity, Severity of Blood Pressure and Serum Albumin. Indian Journal of Physiology and Pharmacology, 43, 193-198.

[7] Larijani, B., Marsoosi, V., Aghakhani, S., Moradi, A. and Hashemipour, S. (2004) Thyroid Hormone Alteration in Pre-Eclamptic Women. Gynecological Endocrinology, 18, 97-100. http://dx.doi.org/10.1080/09513590310001652973

[8] Lao, T.T., Chin, R.K.H. and Swaminathan, R. (1988) Thyroid Function in Pre-Eclampsia. British Journal of Obstetrics \& Gynaecology, 95, 880-883. http://dx.doi.org/10.1111/j.1471-0528.1988.tb06573.x

[9] Başbuğ, M., Aygen, E., Tayyar, M., Tutuş, A., Kaya, E. and Öktem, Ö. (1999) Correlation between Maternal Thyroid Function Tests and Endothelin in Preeclampsia-Eclampsia. Obstetrics \& Gynecology, 94, 551-555. http://dx.doi.org/10.1016/S0029-7844(99)00332-4

[10] Qublan, H.S., Al-Kaisi, I.J., Hindawi, I.M., Hiasat, M.S., Awamleh, I., Hamaideh, A.H., Abd-Alghani, I., Sou’ub, R.M., Abu-Jassar, H. and Al-Maitah, M. (2003) Severe Pre-Eclampsia and Maternal Thyroid Function. Journal of Obstetrics \& Gynaecology, 23, 244-246. http://dx.doi.org/10.1080/0144361031000098334

[11] Neale, D.M., Cootauco, A.C. and Burrow, G. (2007) Thyroid Disease in Pregnancy. Clinics in Perinatology, 34, 543557. http://dx.doi.org/10.1016/j.clp.2007.10.003

[12] Krajewski, D.A. and Burman, K.D. (2011) Thyroid Disorders in Pregnancy. Endocrinology and Metabolism Clinics of North America, 40, 739-763. http://dx.doi.org/10.1016/j.ecl.2011.08.004

[13] Negro, R. and Mestman, J.H. (2011) Thyroid Disease in Pregnancy. Best Practice \& Research Clinical Endocrinology \& Metabolism, 25, 927-943. http://dx.doi.org/10.1016/j.beem.2011.07.010

[14] Dafau, M. and Veldhuis, J. (1987) Pathophysiological Relationships between the Biological and Immunological Activities of Luteinizing Hormone. Baillière’s Clinical Endocrinology and Metabolism, 1, 153-176. http://dx.doi.org/10.1016/S0950-351X(87)80057-5

[15] Jaakkola, T., Ding, Y.Q., Kellokumpu-Lehtinen, P., Valavaara, R., Martikainn, H., Tapanaimen, J., et al. (1990) The Ratios of Serum Bioactive/Immunoactive Luteinizing Hormone and Follicle Stimulating Hormone in Various Clinical Conditions with Increased and Decreased Gonadotropin Secretion: Reevaluation by Highly Sensitive Immunometric Assays. The Journal of Clinical Endocrinology \& Metabolism, 70, 1496-1505. http://dx.doi.org/10.1210/jcem-70-6-1496

[16] Hsu, C.D., Chan, D.W., Iriye, B., Johnson, T.R.B., Hong, S.F. and Repke, J.T. (1994) Elevated Serum Human Chorionic Gonadotropin as Evidence of Secretory Response in Severe Preeclampsia. American Journal of Obstetrics \& Gynecology, 170, 1135-1138. http://dx.doi.org/10.1016/S0002-9378(94)70108-3

[17] Ashour, A.M., Lieberman, E.S., Haug, L.E. and Repke, J.T. (1997) The Values of Elevated Second-Trimester BetaHuman Chorionic Gonadotropin in Predicting Development of Preeclampsia. American Journal of Obstetrics \& Gynecology, 176, 438-442. http://dx.doi.org/10.1016/S0002-9378(97)70512-X

[18] Merviel, P., Müller, F., Guibourdenche, J., Berkane, N., Gaudet, R., Bréat, G. and Uzan, S. (2001) Correlations between Serum Assays of Human Chorionic Gonadotropin (hCG) and Human Placental Lactogen (hLP) and Pre-Eclampsia or Intrauterine Growth Restriction (IUGR) among Nuliparas Younger than 38 Years. European Journal of Obstetrics \& Gynecology and Reproductive Biology, 95, 59-67. http://dx.doi.org/10.1016/S0301-2115(00)00370-5

[19] Barros, J.S., Baptista, M.G. and Bairos, V.A. (2002) Human Chorionic Gonadotropin in Human Placentas from Normal and Preeclamptic Pregnancies. Archives of Gynecology and Obstetrics, 266, 67-71. http://dx.doi.org/10.1007/s004040100181

[20] Bartha, J.L., Romero-Carmona, R., Escobar-Llombar, M., Paloma-Castro, O. and Comino-Delgado, R. (2003) Human Chorionic Gonadotropin and Vascular Endothelial Growth Factor in Normal and Complicated Pregnancies. Obstetrics \& Gynecology, 102, 995-999. http://dx.doi.org/10.1016/S0029-7844(03)00808-1

[21] Kato, K., Mostafa, M.H., Mann, K., Schindler, A.E. and Hoermann, R. (2004) The Human Chorionic Gonadotropin Molecule from Patients with Trophoblastic Diseases Has High Thyrotropic Activity but Is Less Active in the Ovary. Gynecological Endocrinology, 18, 269-277. http://dx.doi.org/10.1080/09513590410001667247

[22] Walkington, L., Webster, J., Hancock, B.W., Everard, J. and Coleman, R.E. (2011) Hyperthyroidism and Human Cho- 
rionic Gonadotropin Production in Gestational Trophoblastic Disease. British Journal of Cancer, 104, 1665-1669. http://dx.doi.org/10.1038/bjc.2011.139

[23] Yoshimura, M., Pekary, A.E., Pang, X.P., Berg, L., Goodwin, T.M. and Hershman, J.M. (1994) Thyrotropic Activity of Basic Isoelectric Forms of Human Chorionic Gonadotropin Extracted from Hydatidiform Mole Tissues. Journal of Clinical Endocrinology \& Metabolism, 78, 862-866.

[24] Goodwin, T.M., Montoro, M., Mestman, J.H., Pekary, A.E. and Hershman, J.M. (1992) The Role of Chorionic Gonadotropin in Transient Hyperthyroidism of Hyperemesis Gravidarum. Journal of Clinical Endocrinology \& Metabolism, 75, 1333-1337.

[25] Hershman, J.M. (2004) Physioloical and Pathological Aspect of the Effect of Human Chorionic Gonadotropin on the Thyroid. Best Practice \& Research Clinical Endocrinology \& Metabolism, 18, 249-265. http://dx.doi.org/10.1016/j.beem.2004.03.010

[26] Verberg, M.F.G., Gillott, D.J., Al-Fardan, N. and Grudzinskas, J.G. (2005) Hyperemesis Gravidarum, a Literature Review. Human Reproduction Update, 11, 527-539. http://dx.doi.org/10.1093/humupd/dmi021

[27] Wier, F. and Farley, C. (2006) Clinical Controversies in Screening Women for Thyroid Disorders during Pregnancy. Journal of Midwifery Women's Health, 51, 152-158. http://dx.doi.org/10.1016/j.jmwh.2005.11.007

[28] Semlitsch, G., Buchinger, W., Reiterer, E., Binter, G. and Rainer, F. (2000) Measurement of Free Triiodothyronine (FT3) Using an Electrochemiluminescence Immunoassay in Patients with Autoantibodies to Triiodothyronine. Acta Medica Austriaca, 27, 54-55.

[29] Sonan, M., Hiraoka, K., Yamada, E., Watanabe, S. and Kobayaski, M. (2001) Fundamental and Clinical Evaluation of TSH and Thyroid Hormone Measurement by Electrochemiluminescence Immunoassay System Modular Analytics (EE). Jpn J Med Pharm Sci., 46, 759-771.

[30] Casart, Y.C., Camejo, M.I., Proverbio, F. and Febres, F. (2001) Bioactivity of Serum hCG in Preeclampsia. Obstetrics \& Gynecology, 98, 463-465. http://dx.doi.org/10.1016/S0029-7844(01)01463-6

[31] Huang, S.C., Hwang, J.L., Hsieh, C.Y., Chen, R.J. and Ouyang, P.C. (1989) Human Chorionic Gonadotropin and Its Subunits in Pre-Eclampsia. Taiwan Yi Xue Hui Za Zhi, 88, 132-136.

[32] Wenstrom, K.D., Owen, J., Boots, L.R. and DuBard, M.B. (1994) Elevated Second-Trimester Human Chorionic Gonadotropin Levels in Association with Poor Pregnancy Outcome. American Journal of Obstetrics \& Gynecology, 171, 1038-1041. http://dx.doi.org/10.1016/0002-9378(94)90030-2

[33] Cole, L.A. (2009) New Discoveries on the Biology and Detection of Human Chorionic Gonadotropin. Reproductive Biology and Endocrinology, 26, 7-8.

[34] Hoermann, R., Keutmann, H.T. and Amir, S.M. (1991) Carbohydrate Modifications Transform Human Chorionic Gonadotropin into a Potent Stimulator of Adenosine 3',5'-Monophosphate and Growth Responses in FRTL-5 Thyroid Cells. Endocrinology, 128, 1129-1135. http://dx.doi.org/10.1210/endo-128-2-1129

[35] Pekary, A.E., Jackson, I.M.D., Goodwin, T.M., Pang, X.P., Hein, M.D. and Hershman, J.M. (1993) Increased in Vitro Thyrotropic Activity of Partially Sialated Human Chorionic Gonadotropin Extracted from Hydatidiform Moles of Patients with Hyperthyroidism. Journal of Clinical Endocrinology \& Metabolism, 76, 70-74.

[36] Yoshimura, M., Hershman, J.M., Pang, X.P., Berg, L. and Pekary, A.E. (1993) Activation of the Thyrotropin (TSH) Receptor by Human Chorionic Gonadotropin and Luteinizing Hormone in Chinese Hamster Ovary Cells Expressing Functional Human TSH Receptors. Journal of Clinical Endocrinology \& Metabolism, 77, 1009-1013.

[37] Hoermann, R., Kubota, K. and Amir, S.M. (1993) Role of Subunit Sialic Acid in Hepatic Binding, Plasma Survival Rate, and in Vivo Thyrotropic Activity of Human Chorionic Gonadotropin. Thyroid, 3, 41-47. http://dx.doi.org/10.1089/thy.1993.3.41

[38] Glinoer, D. (1997) The Regulation of Thyroid Function in Pregnancy: Pathways of Endocrine Adaptation from Physiology to Pathology. Endocrine Reviews, 18, 404-433. http://dx.doi.org/10.1210/edrv.18.3.0300

[39] Cole, L.A. (2012) hCG, Five Independent Molecules. Clinica Chimica Acta, 413, 48-65. http://dx.doi.org/10.1016/j.cca.2011.09.037 